\title{
Deformação da cobertura com embasamento envolvido em caixas de areia: estudo de caso da região da Serra da Água Fria (MG), Bacia São Francisco
}

\author{
Caroline Janette Souza Gomes ${ }^{1}$, André Danderfer Filho ${ }^{2}$ \& Cízia Mara Hercos ${ }^{3}$
}

\begin{abstract}
Resumo Modelos experimentais foram empregados para testar uma interpretação tectônica da região da serra da Água Fria, localizada a nordeste da serra do Cabral, na porção leste do Craton São Francisco (MG). Em três experimentos investigou-se o efeito de diferentes materiais analógicos sobre o encurtamento progressivo de uma bacia extensional, constituída por grábens e horsts posicionados sobre um descolamento basal intracrustal. O intuito do estudo era analisar a dupla vergência de falhas reversas sobre o Alto do Boqueirão, um alto do embasamento, e dobras induzidas por falhamentos de polaridade contrária ao sentido do transporte tectônico regional na sequência pós-rifte. O experimento I foi montado somente com areia colorida, simulando o comportamento rúptil, enquanto que nos experimentos II e III introduziu-se na sequência pós-rifte uma anisotropia basal, mediante o uso de microesferas de vidro e cristais de mica, respectivamente. Os experimentos revelaram que a hipótese de que um bloco de embasamento, situado sobre um descolamento intracrustal, possa ter agido inicialmente como um obstáculo à deformação progressiva durante a inversão tectônica, e posteriormente, ao se tornar móvel, como um indenter, é geométrica e cinematicamente viável. Nesta condição, demonstrou-se que o bloco do embasamento induz falhas reversas com dupla vergência na sequência pós-rifte. Além disso, os experimentos revelaram que a introdução de um material incompetente, especialmente de microesferas de vidro, confere à camada de areia sobreposta, uma reologia rúptil-dúctil. A este comportamento atribuiu-se a formação de fault-propagation folds durante a compressão, tais como caracterizadas sobre o bloco móvel do embasamento na região da serra da Água Fria.
\end{abstract}

Palavras-chave: modelagem física analógica; inversão tectônica; deformação com embasamento envolvido; dupla vergência de falhas reversas; bacia do São Francisco.

\begin{abstract}
Basement-involved deformation in sandbox experiments: a case study from the Água Fria Range region (MG), São Francisco basin, Minas Gerais, Brazil. Sandbox analogue models were used to investigate the structural evolution of the Água Fria Range region, located in the northeast of the Cabral Range, at the east portion of the São Francisco Craton, central Brazil. We investigate the effect of different analogue material during progressive shortening of a previous extensional basin, consisting of horst and grabens detaching above an intracrustal décollement. The study focused on double vergent reverse faults above a basement high, the Boqueirão High, and on hinterland vergent fault-related folds, both in the post-rift sequence. The model 1 was performed entirely with brittle, colored sand whereas in the models 2 and 3 we introduced a less competent layer at the base of the post-rift sequence, composed of glass microbeads and mica flakes, respectively. The three experiments demonstrate that when in inversion tectonics a basement block acts as a buttress and with progressive deformation as an indenter, doubly-verging thrusts in the post-rift sequence were produced. In addition, the experiments demonstrate that the presence of weak glass microbeads induces brittle-ductile behavior in the overlying sand layers. This may explain the formation of fault-propagation folds, above the Boqueirão High around the Água Fria Range.
\end{abstract}

Keywords: physical analogue modeling; inversion tectonics; thick-skinned deformation; double vergent reverse faults; São Francisco basin.

INTRODUÇÃO No presente trabalho investiga-se um modelo tectônico por meio de experimentos, em caixa de areia, para demonstrar a formação de falhas reversas e a sua interferência com retrocavalgamentos, em um ambiente de inversão tectônica. O estudo se baseia no trabalho de Hercos et al. (2008) realizado em um segmento neoproterozóico da porção oriental da bacia do São Francisco, região centro-norte de Minas Gerais (Fig. 1). Os autores caracterizaram em seções sísmicas falhas reversas com dupla vergência na sequência pós-rifte, correspondente à porção superior argilo-carbonática do Supergrupo São Francisco.

Em geral, um sistema de falhas de empurrão de baixo ângulo que compõe um cinturão compressional apresenta polaridade tectônica para o antepaís. No entanto, algumas vezes são observadas falhas de empurrão com cinemática contrária (back-thrusts), situação que caracteriza uma dupla vergência. Em cinturões de 

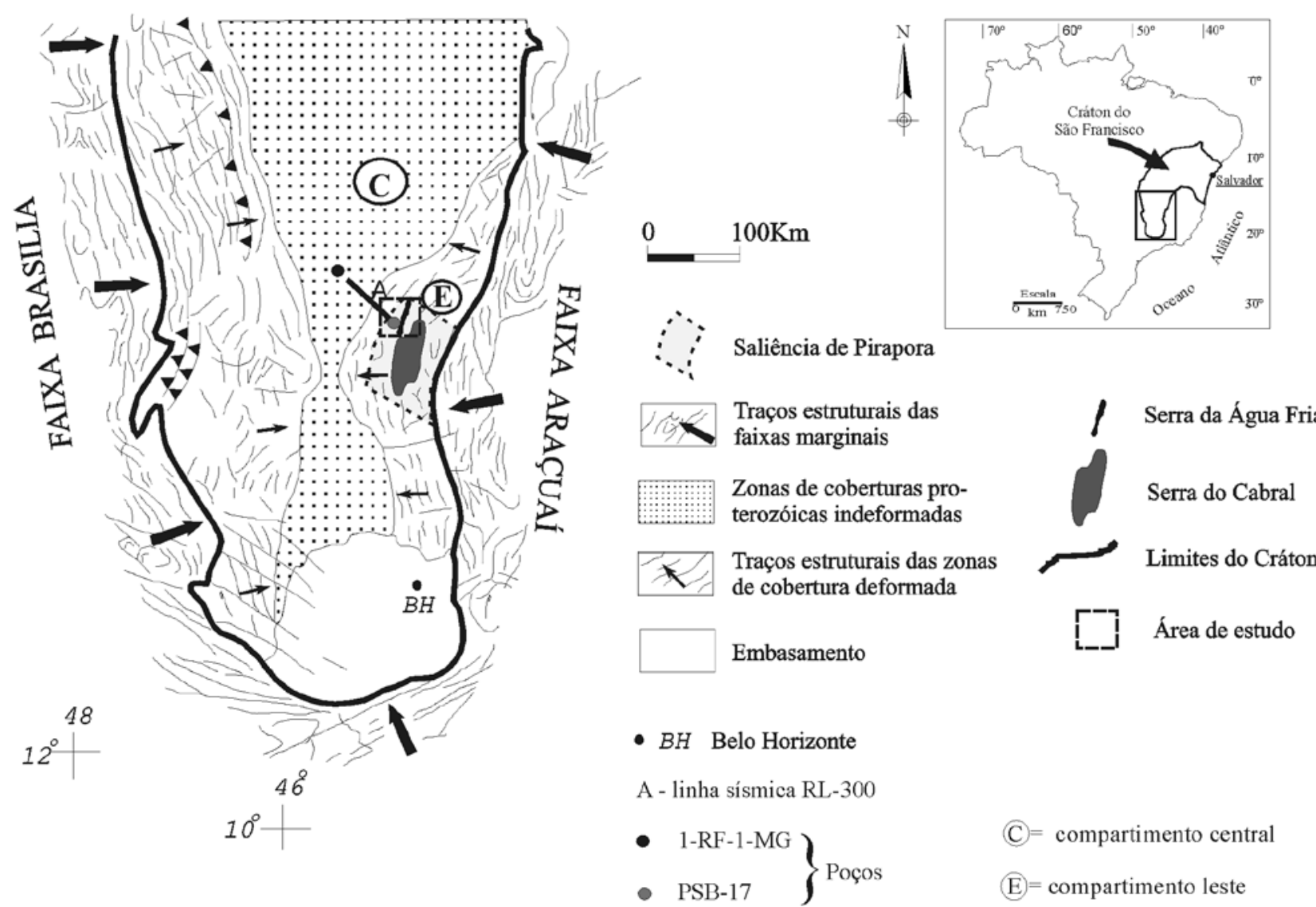

Figura 1 - Localização da área de trabalho no Cráton São Francisco (modificado de Alkmim et al. 1993).

dobras e falhas, a vergência das estruturas é essencialmente controlada pela orientação do eixo principal de esforço $\left(\sigma_{1}\right)$, que determina o ângulo de mergulho das falhas. Chapple (1978) e Davis \& Engelder (1985) discutem o problema do controle do atrito basal sobre o desenvolvimento de falhas vergentes para o antepaís e o pós-país. Os autores demonstram que um elevado ângulo de atrito basal conduz ao posicionamento do $\sigma_{1}$ no sentido do antepaís e inclinado em relação à superfície do descolamento basal. O resulta gera o deslocamento preferencial sobre empurrões de baixo ângulo e, secundariamente, movimentos sobre retrocavalgamentos de alto ângulo. A presença de um descolamento basal dúctil favorece a posição aproximadamente horizontal do $\sigma_{1} \mathrm{e}$, consequentemente, a indução de uma dupla vergência na qual ambas as falhas possuem alto ângulo de mergulho.

Hercos et al. (2008) relacionaram a dupla vergência da região da serra da Água Fria (Figs. 2A e B) a uma situação diferente e peculiar. Segundo os autores, a dupla vergência nessa região seria resultado da movimentação reversa de um bloco de embasamento durante a reativação de uma falha intracrustal normal de baixo ângulo. Com a deformação agindo de leste para oeste, o bloco teria atuado inicialmente como um anteparo fixo, causando um encurtamento e a reativação da falha de borda oeste do domínio leste do segmento estudado. Com a deformação progressiva, o bloco do embasamento teria sido transladado no sentido oeste, juntamente com o depósito sin-rifte. Desta mudança de comportamento, de bloco fixo a móvel, teria resultado a deformação em foco. Ao se deslocar, o bloco teria assumido o papel de um indenter, induzindo a ocorrência de falhas de empurrão e de retroempurrão no seu antepaís, estas últimas responsáveis pela complexa interferência de falhas no pós-rifte, posicionado acima do bloco tectonicamente invertido - o Alto do Boqueirão.

Com o objetivo de testar a viabilidade do modelo de dupla vergência no domínio do Alto do Boqueirão, foram desenvolvidas três modelagens experimentais. Nesses, variou-se o material analógico posicionado na base da sequência pós-rifte, com a finalidade de investigar a influência de um material incompetente na deformação. Na primeira modelagem, as sequências sin e pós-rifte foram simuladas como sistemas acamadados rúpteis e homogêneos, ao passo que nas demais, foi introduzida uma camada basal incompetente na sequência pós-rifte. No segundo experimento, a camada incompetente foi simulada por microesferas de vidro, de granulometria variando entre 0,18 e $0,30 \mathrm{~mm}$, e no terceiro, por cristais de mica de diâmetro próximo a 1 $\mathrm{mm}$. Ambos os materiais possuem coeficiente de atrito mais baixo que o da areia seca.

CONTEXTO GEOLÓGICO O segmento modelado compreende os compartimentos indeformado ( $\mathrm{C}$ - central) e deformado de antepaís (E - leste) da porção oriental do 


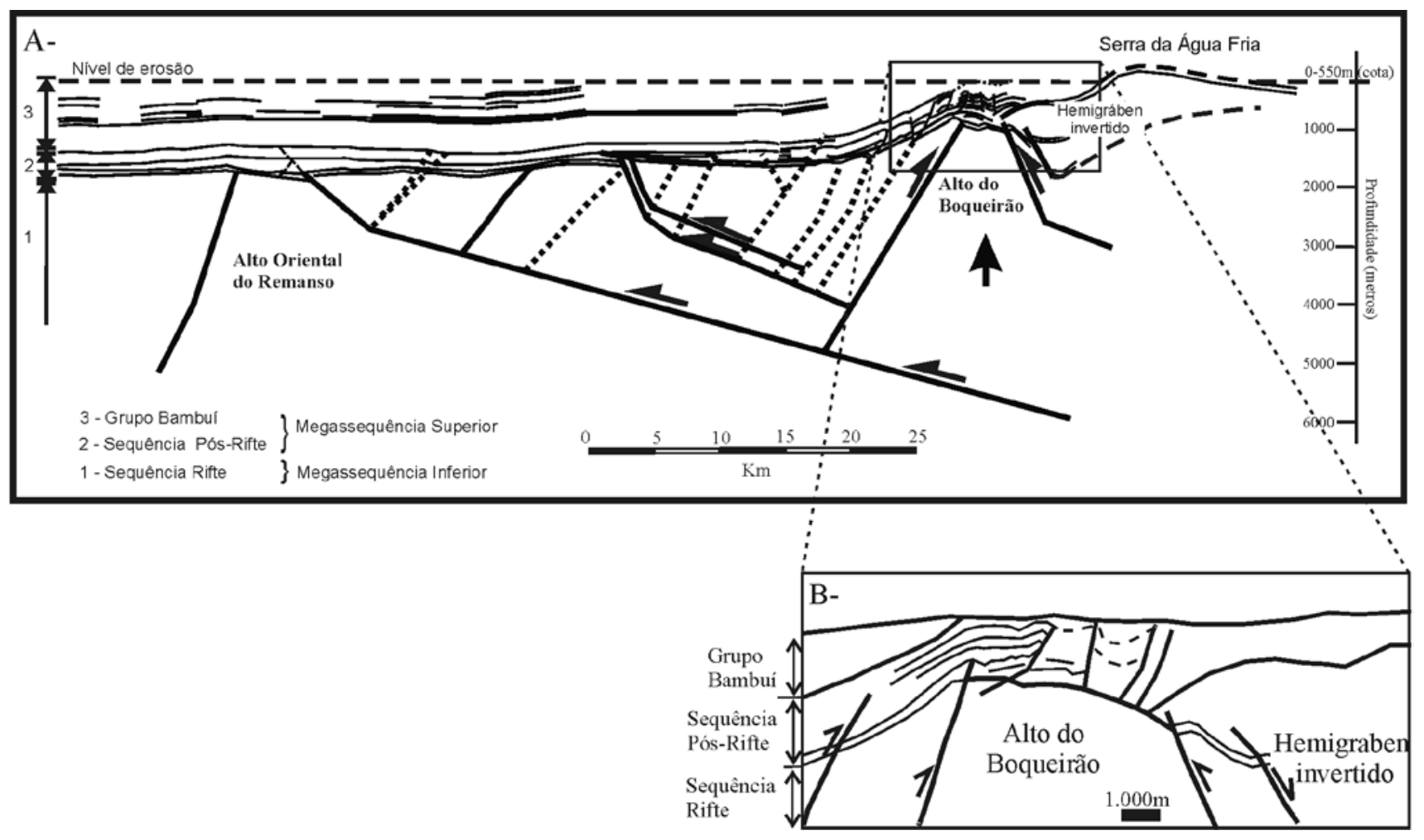

Figura 2 - A- A seção sísmica $R L-300$, em tempo, redesenhada, com interpretação dos traços estruturais. $B$ - $A$ região do Alto do Boqueirão amplificada.

cráton São Francisco (Fig. 1), tal como definidos por Alckmin et al. (1993). No compartimento E, as rochas da cobertura cratônica apresentam deformação epidérmica (thin-skinned), com mecanismo motriz focado no interior da Faixa Araçuaí, posicionada a leste do cráton.

De modo diverso, Hercos et al. (2008) posicionaram o segmento modelado em um compartimento onde o embasamento foi envolvido na deformação das rochas da cobertura (tectônica thick-skinned), denominando-o Saliência de Pirapora. Segundo os autores, os elementos estruturais predominantes nessa área são dobras na cobertura e falhas, na porção mais profunda da seção. Através da sísmica, os autores observaram que a geração das dobras foi induzida por falhas (fault-related folds), enraizadas em descolamentos, ou a partir da reativação de falhas normais com cinemática inversa. Em profundidade, nos arredores da serra da Água Fria foi interpretado um hemigráben invertido balizado a oeste por um alto de embasamento (o Alto do Boqueirão), recoberto por uma unidade que exibe maior encurtamento acomodado por megadobras.

Com base nos dados de subsuperfície da área (seção sísmica RL-300), Hercos (2008) propôs a existência de duas megassequências deposicionais: uma basal de caráter extensional (Megassequência Inferior), constituindo o preenchimento de grábens e hemigrábens limitados por horsts (inclui as unidades do Supergrupo Espinhaço e da fase rifte do Grupo Macaúbas), e uma superior (Megassequência Superior), com estratos paralelos a subparalelos que recobrem as estruturas tafrogênicas (fase flexural do Grupo Macaúbas e sequências do
Grupo Bambuí), limitadas entre si por uma discordância de caráter regional. Em superfície, na serra da Água Fria, afloram sequências predominantemente areníticas correlacionadas na literatura às formações superiores do Grupo Conselheiro Mata (Supergrupo Espinhaço). Sobre os arenitos, assentam-se em discordância depósitos areno-diamictíticos e conglomeráticos, glaciogênicos, da Formação Jequitaí, correlacionados ao Grupo Macaúbas e posicionados na fase rifte da bacia homônima. Os depósitos da Formação Jequitaí são capeados por intercalações de pelito-carbonato-arenito (fase flexural do Grupo Macaúbas) que evoluem para uma seção eminentemente pelito-carbonática em direção ao topo (Grupo Bambui), os quais afloram na serra da Onça (Hercos 2008).

\section{A MODELAGEM ANALÓGICA}

Os materiais analógicos Empregou-se a areia de quartzo para representar os sistemas acamadados, sin e pós-rifte, as rochas clásticas das megassequências superior e inferior da região da serra da Água Fria. Microesferas de vidro, assim como cristais de micas, foram utilizados para simular as rochas incompetentes da fase flexural do Grupo Macaúbas (base da Megassequência Superior), do tipo pelitos e calcários.

As propriedades friccionais dos materiais analógicos empregados no presente trabalho encontram-se listadas na tabela 1 .

A areia de quartzo seca possui comportamento Mohr-Coulomb, em um campo de gravidade natural, conforme estudos efetuados, entre outros, por Hubbert (1951), Ramberg (1981), Davy \& Cobbold 
(1988 e 1991) e Schellart (2000). No presente trabalho utilizou-se areia de quartzo, de grãos sub-angulares, e granulometria entre 0,25 e $0,50 \mathrm{~mm}$, colorida artificialmente, com tinta de tecido Acrilex. Medidas efetuadas no Ring-Shear Tester - RST- 01.pc do GeoForschungsZentrum (GFZ) Potsdam (Alemanha), sob baixas condições de tensões normais, forneceram para a areia um comportamento elasto-plástico, e valores de ângulo de atrito interno, $\Phi$, de de $39^{\circ}(\mu=0,81)$ e de coesão aparente, C, de $60 \mathrm{~Pa}$ (Gomes et al. 2009).

$\mathrm{O}$ emprego de microesferas de vidro para a simulação de camadas incompetentes, se baseou nos estudos de Schellart (2000) e Panien et al. (2005 e 2006). $\mathrm{O}$ alto grau de arredondamento das microesferas contribui para a redução da coesão e do coeficiente de atrito interno, o que lhe confere propriedades mecânicas mais dúcteis do que as da areia de quartzo. Panien et al. (2006), utilizando microesferas de vidro de granulometria variando entre 0,07 e $0,11 \mathrm{~mm}$, obtiveram no mesmo Ring-Shear Tester, do GFZ Potsdam, um ângulo de atrito interno, $\Phi$, de $22,3^{\circ}(\mu=0,41)$ e coesão aparente, $\mathrm{C}$, de $25 \mathrm{~Pa}$. No presente trabalho, apesar das microesferas de vidro serem de origem e granulometria diferentes, adotou-se como valores de referência, aqueles determinados pelos autores acima.

McClay (1990), Storti \& McClay (1995) e Gomes et al. (1999) introduziram em sistemas acamadados de areia de quartzo, horizontes de vermiculita ou mica, visando a geração de anisotropias mecânicas. A determinação das características friccionais de agregados de micas, em estado não-compactado, foi efetuada por Ellis (1988) que, para esta finalidade, usou um aparelho de cisalhamento simples, empregado na Mecânica dos Solos. Para uma tensão normal de $12,2 \times 10^{3} \mathrm{~Pa}$, o autor obteve um comportamento não linear, elasto-plástico, no diagrama de tensão cisalhante x deformação, e linear, de Coulomb, no diagrama de Mohr. O ângulo de atrito interno corresponde a $30^{\circ}(\mu=0,58)$ e a coesão a $0 \mathrm{~Pa}$.

A escala Os modelos em escala foram montados seguindo-se os princípios da similaridade geométrica, cinemática e dinâmica, postulados por Hubbert (1937) e Ramberg (1981). As razões de escala entre modelo e natureza, empregados no presente estudo, encontramse listados na tabela 2 .

Pelo princípio da similaridade dinâmica (Hubbert 1937), a razão das tensões entre modelo $\left(\sigma_{\text {mod }}\right)$ e natureza $\left(\sigma_{\text {original }}\right)$ pode ser calculado pela equação 1 :

$$
\sigma_{\mathrm{r}}=\sigma_{\text {mod }} / \sigma_{\text {original }}=\lambda \cdot \rho \cdot \mathrm{g}^{*}
$$

onde $\lambda, \rho$ e g* são, respectivamente, as razões dos comprimentos, das densidades e das acelerações da gravidade. Para os fins da modelagem física analógica a $\sigma_{\text {mod }}$ corresponde à tensão cisalhante coesiva (em geral, referido apenas como coesão) do material analógico. Considerando-se comportamento Mohr-Coulomb, para modelo e natureza, e tensão cisalhante coesiva média de rochas intactas de $2 \times 10^{7}$ (Handin 1966), então, pela equação (1), a coesão do material analógico empregado, neste trabalho, deveria ser:

$$
\begin{aligned}
& \sigma_{\mathrm{r}}=\sigma_{\text {mod }} / \sigma_{\text {original }}=\left(2 \times 10^{-5}\right) \times(0,5) \times(1) \\
& \sigma_{\text {mod }}=\left(2 \times 10^{-5}\right) \times(0,5) \times(1) \times\left(2 \times 10^{7}\right) \\
& \sigma_{\text {mod }}=200 \mathrm{~Pa}
\end{aligned}
$$

O fato de que o valor calculado a partir da equação (1) e a magnitude da coesão determinado no Ring-Shear Tester, do GFZ Potsdam, se encontrem na mesma ordem de grandeza demonstra que os modelos satisfazem o critério da similaridade dinâmica.

Tabela 1 - Propriedades friccionais dos materiais analógicos empregados: areia seca, microesferas de vidro e cristais de mica.

\begin{tabular}{c|c|c|c|c}
\hline Material analógico & $\begin{array}{c}\text { Ângulo de atrito } \\
\text { interno }(\Phi)\end{array}$ & $\begin{array}{c}\text { Coeficiente de atrito } \\
\text { interno }(\mu)\end{array}$ & $\begin{array}{c}\text { Tensão cisalhante } \\
\text { coesiva }(\mathrm{C})\end{array}$ & Autor(es) \\
\hline Areia seca & $39^{\circ}$ & 0,81 & $60 \mathrm{~Pa}$ & Gomes et al. (2009) \\
\hline $\begin{array}{c}\text { Microesferas de } \\
\text { vidro }\end{array}$ & $22,3^{\circ}$ & 0,41 & $25 \mathrm{~Pa}$ & Panien et al. (2006) \\
\hline Cristais de micas & $30^{\circ}$ & 0,58 & $0 \mathrm{~Pa}$ & Ellis (1988) \\
\hline
\end{tabular}

Tabela 2 - Parâmetros de escala.

\begin{tabular}{c|c|c|c}
\hline Parâmetro & Modelo & Natureza & $\begin{array}{c}\text { Razão Modelo/ } \\
\text { Natureza }\end{array}$ \\
\hline Comprimento $(\mathrm{L})$ & $0,37 \mathrm{~m}$ & $74 \times 10^{3} \mathrm{~m}$ & $\lambda=2 \times 10^{-5}$ \\
\hline Densidade $(\mathrm{d})$ & $1,2-1,4 \mathrm{~kg} / \mathrm{m}^{3}$ & $2,4-2,8 \mathrm{~kg} / \mathrm{m}^{3}$ & $\rho \sim 0,5$ \\
\hline Gravidade $(\mathrm{g})$ & $9,8 \mathrm{~m} / \mathrm{s}^{2}$ & $9,8 \mathrm{~m} / \mathrm{s}^{2}$ & $\mathrm{~g}^{*}=1$ \\
\hline $\begin{array}{c}\text { Tensão coesiva }(\tau) \\
(\mathrm{Pa})\end{array}$ & $0-60$ & $2 \times 10^{7 * *}$ & $\sigma \mathrm{r}<10^{-5}$ \\
\hline
\end{tabular}

\footnotetext{
${ }^{(* *)}$ valores de Handin (1966)
} 
Os modelos experimentais - Procedimentos Três modelos experimentais (I, II e III) foram desenvolvidos em uma caixa retangular de $37 \mathrm{~cm}$ de comprimento e $20 \mathrm{~cm}$ de largura, limitada lateralmente por paredes de vidro transparentes. Nesta caixa, a deformação foi induzida por um motor elétrico a uma velocidade constante de $2 \mathrm{~cm} / \mathrm{h}$.

Com base no perfil sísmico de Hercos et al. (2008; Fig. 2A), foram montados, no interior da caixa, uma falha normal mestra de baixo ângulo (a falha intracrustal) e três altos do embasamento, em blocos de acrílico (Fig. 3). Para facilitar a descrição dos experimentos, o bloco da extremidade leste será, doravante, denominado de Alto do Boqueirão, conforme designação no perfil sísmico da figura 2 .
Em função do pouco conhecimento relativo à fase distensiva, simulou-se apenas a etapa de compressão, ou seja, os processos de inversão tectônica da bacia. A caixa de experimento foi montada de maneira a gerar a deformação compressiva em duas etapas. Na primeira, gerou-se um encurtamento de $2 \mathrm{~cm}$ no domínio entre o Alto do Boqueirão e a parede móvel da caixa, o domínio leste da bacia, e na segunda, uma compressão de mais 4 $\mathrm{cm}$, na região a oeste do Alto do Boqueirão.

Para a realização da segunda etapa lançou-se mão do seguinte artifício: colou-se, previamente, na base do Alto do Boqueirão uma folha de cartolina, rígida, coberta por papel contact, estendendo-a por sob a parede móvel da caixa do experimento. Esta folha de cartolina permaneceu desativada durante a primeira

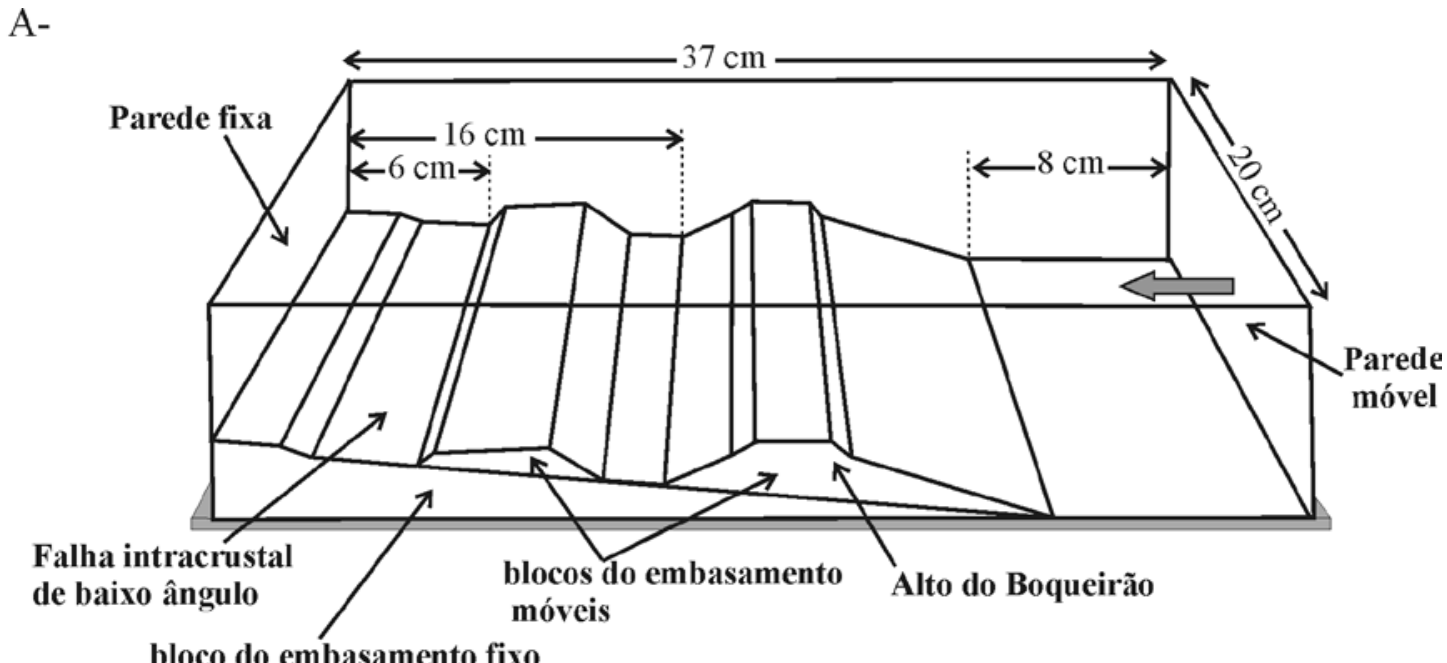

B-

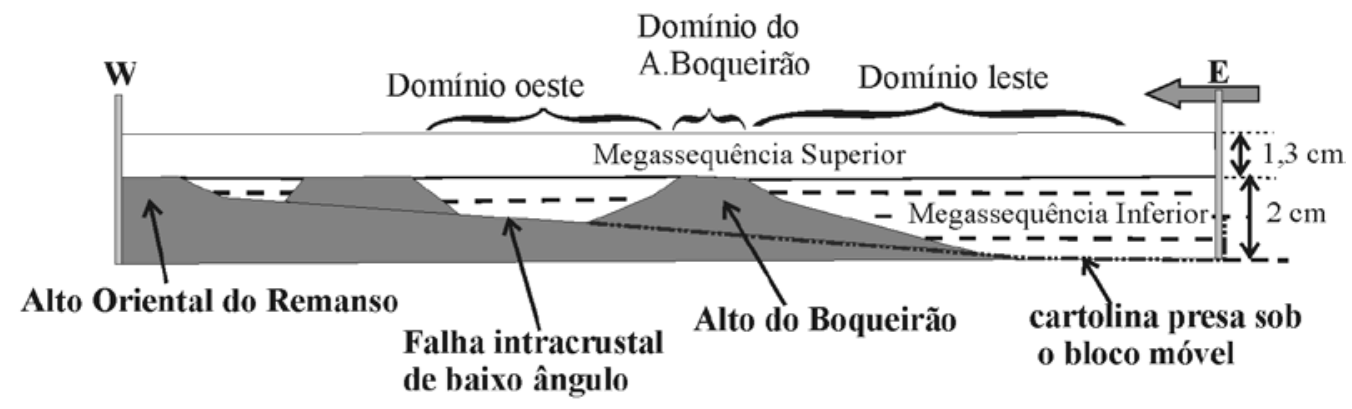

C-

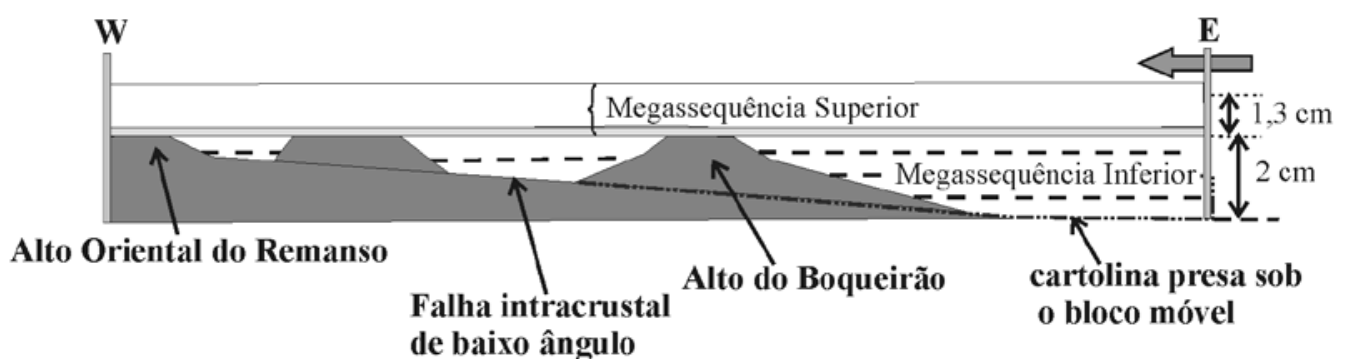

Figura 3 - A- Caixa do experimento, em 3D, vazia, com os blocos do embasamento, em acrílico. B- Caixa preenchida com areia simulando as megassequências inferior e superior, em perfil (experimento I). C-Caixa preenchida com areia e um horizonte de material incompetente (espessura: $2 \mathrm{~mm}$ ), na base da Megassequencia Superior, em perfil (experimentos II e III). A seta indica o sentido do movimento da parede móvel. 
etapa de compressão, porém na segunda etapa, foi presa à parede móvel de maneira a promover o encurtamento no domínio oeste da bacia.

A caixa foi preenchida por duas sequências de areias, em finas camadas de cores distintas, totalizando $3,3 \mathrm{~cm}$ de espessura. O pacote basal representa unidades do Supergrupo Espinhaço e da fase rifte do Grupo Macaúbas (Megassequência Inferior) preenchendo as bacias homônimas, e o topo, a fase flexural do Grupo Macaúbas e sequências do Grupo Bambuí (Megassequência Superior). O pacote basal, também referido como sequência sin-rifte, ocupou o espaço entre os blocos do embasamento e nivelou o topo da primeira sequência a uma altura de $2 \mathrm{~cm}$. Nos experimentos II e III introduziu-se na base do pacote de topo - a sequência pós-rifte - uma fina camada, de $2 \mathrm{~mm}$ de espessura, constituída por microesferas de vidro e de cristais de micas, respectivamente.

A compressão nos modelos foi gerada por um motor elétrico, a uma velocidade de $2 \mathrm{~cm} / \mathrm{h}$. Após a deformação, os experimentos foram umedecidos com água e seccionados por três cortes verticais, paralelos ao transporte tectônico, possibilitando uma análise 3D das estruturas e minimizando o efeito do atrito lateral do vidro. A deformação progressiva dos experimentos foi documentada, em intervalos de $1 \mathrm{~cm}$, por fotografias tiradas através da parede lateral de vidro.

DESCRIÇÃO DOS EXPERIMENTOS As figuras 4, 5 e 6 mostram fotografias da deformação progressiva dos três experimentos, obtidas através da parede lateral

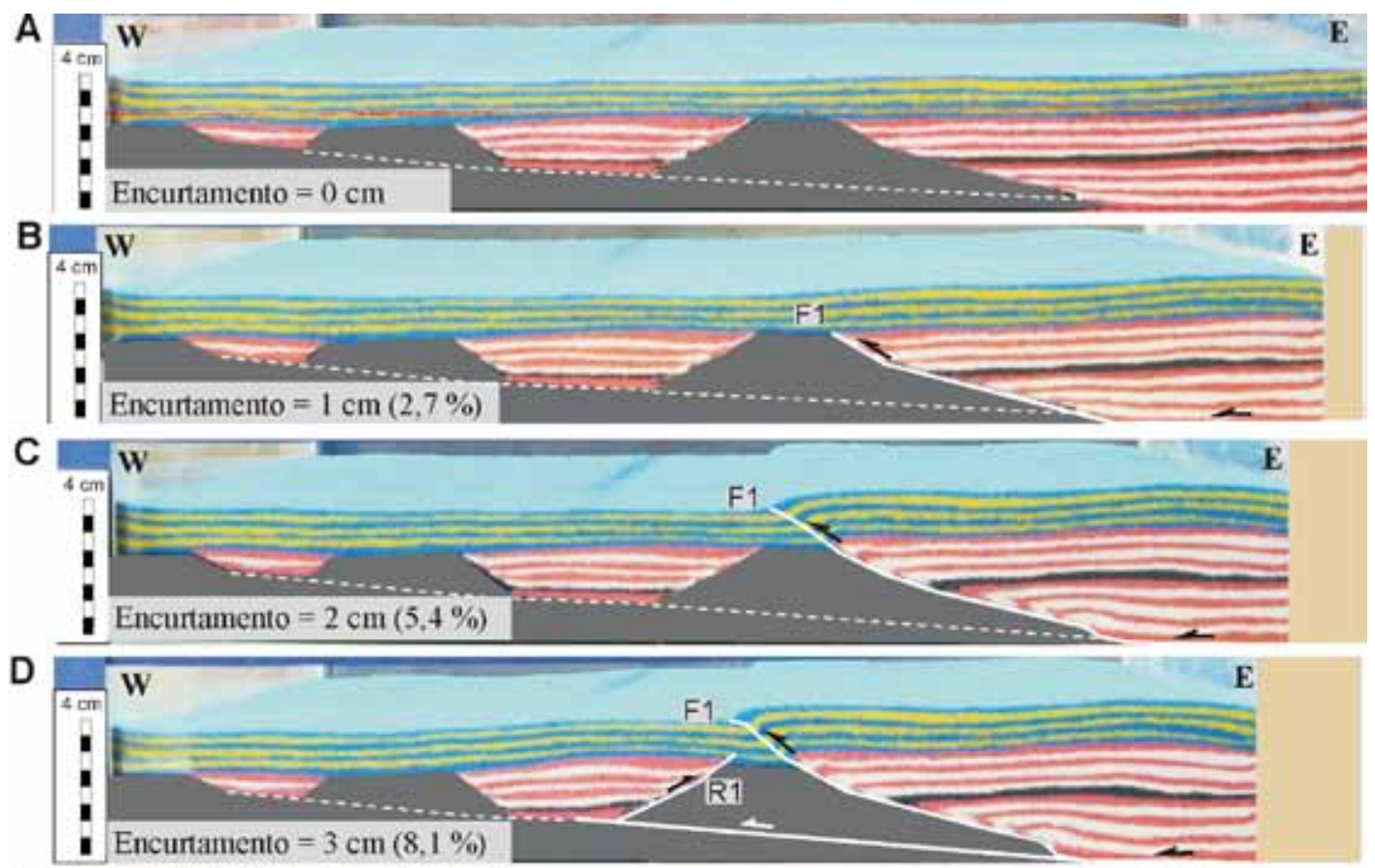

E

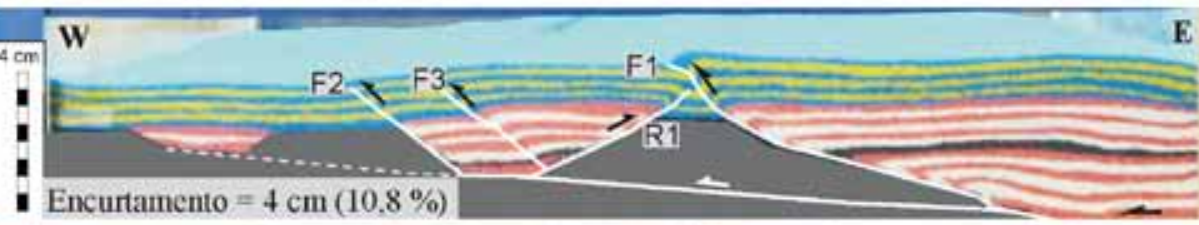

F

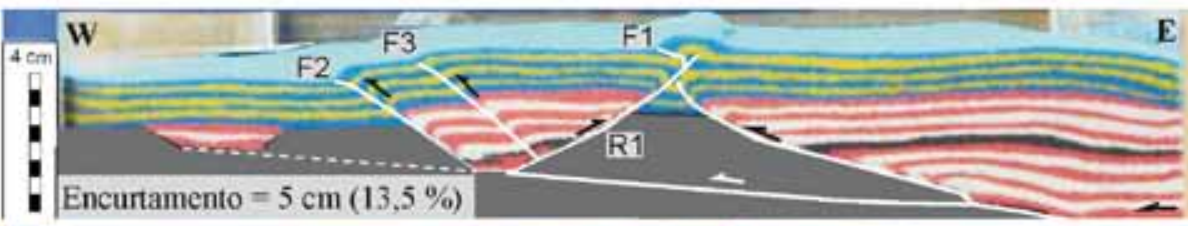

G

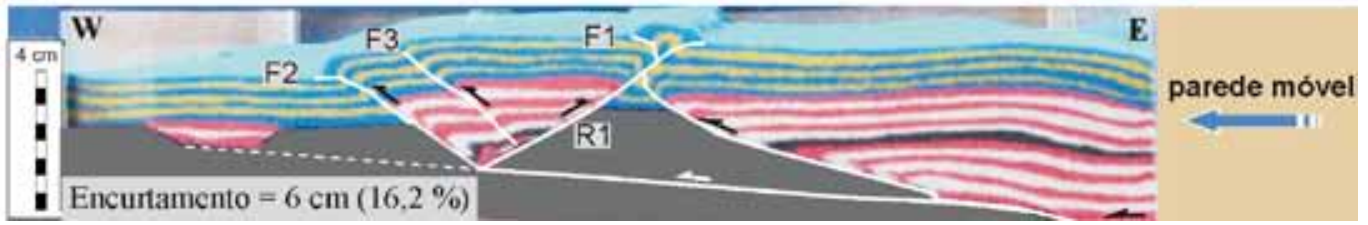

Figura 4 - A a $G$ - Deformação progressiva do experimento I, constituído pelas megassequências inferior e superior, de areia seca. F1, F2 e F3 = falhas reversas; $R 1=$ retroempurrão. $A$ linha tracejada nas figuras $A-D$ representa a falha normal intracrustal, antes de sua reativação. 

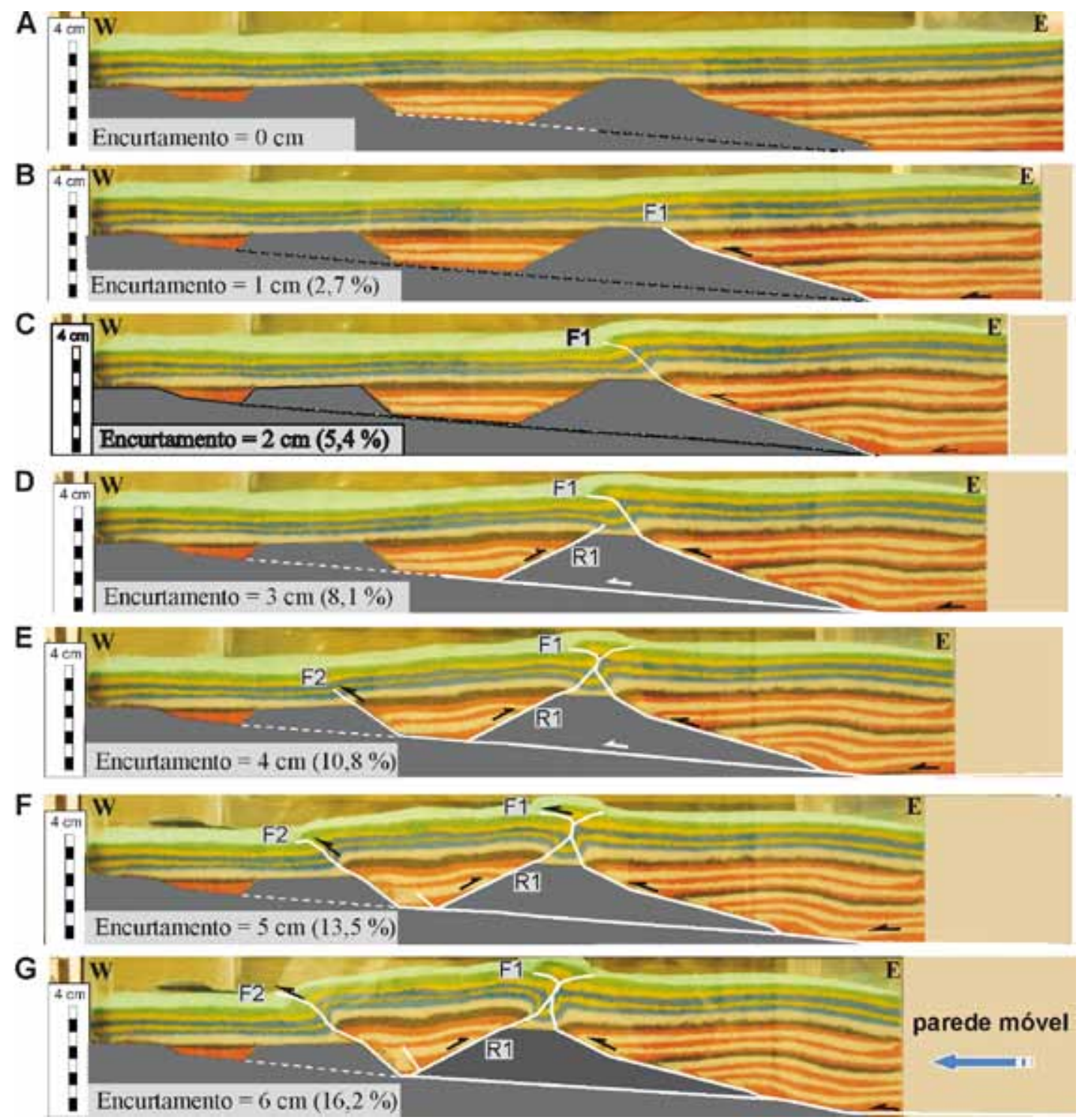

Figura 5 - A a $G$ - Deformação progressiva do experimento II, com uma camada basal de microesferas de vidro na base da megassequência superior. F1 e F2 = falhas reversas; $R 1$ = retroempurrão. A linha tracejada nas figuras $A-D$ representa a falha normal intracrustal, antes de sua reativação.

de vidro, e as figuras 7, 8 e 9 os respectivos cortes internos, ao final da deformação.

O domínio leste Os três experimentos apresentam após $2 \mathrm{~cm}$ de encurtamento, uma deformação similar. As feições mais expressivas desta etapa de deformação são: a nucleação de uma falha reversa (F1) ao longo da face oriental do Alto do Boqueirão e, associada a esta, uma dobra de arrasto. Esta dobra produz em todos os experimentos um relevo positivo que, com a deformação progressiva, é amplificado, em decorrência da atuação de um retroempurrão no domínio oeste.

Nota-se que, no início da segunda etapa de deformação, o rejeito da falha ainda cresce, mas, a partir de $3 \mathrm{~cm}$ de encurtamento, a translação sobre o empurrão $F 1$ cessa por completo. Inicia-se, então, a formação das estruturas no domínio oeste.
Os domínios central (do Alto do Boqueirão) e oeste A segunda etapa de encurtamento é caracterizada pela formação de um novo empurrão (F2), que passa por baixo do Alto do Boqueirão e ascende ao longo do segundo bloco rígido (limite ocidental do domínio oeste), até aflorar. Em todos os experimentos, além da falha F2, um retroempurrão (R1) se desenvolve ao longo da face ocidental do bloco do Boqueirão. O movimento conjunto destas duas falhas gera no domínio oeste uma estrutura do tipo pop-up, simétrica nos experimentos II (com microesferas de vidro) e III (com cristais de micas) e assimétrica no experimento I (constituído apenas por areia seca). É importante notar que, em todos os experimentos a translação da sequência sin-rifte ao longo da falha R1 causa uma vergência contrária no domínio sobre o Alto do Boqueirão, e que deste movimento resulta uma superposição da falha R1 sobre a F1. A análise cuidadosa dos três experimentos revelou que 

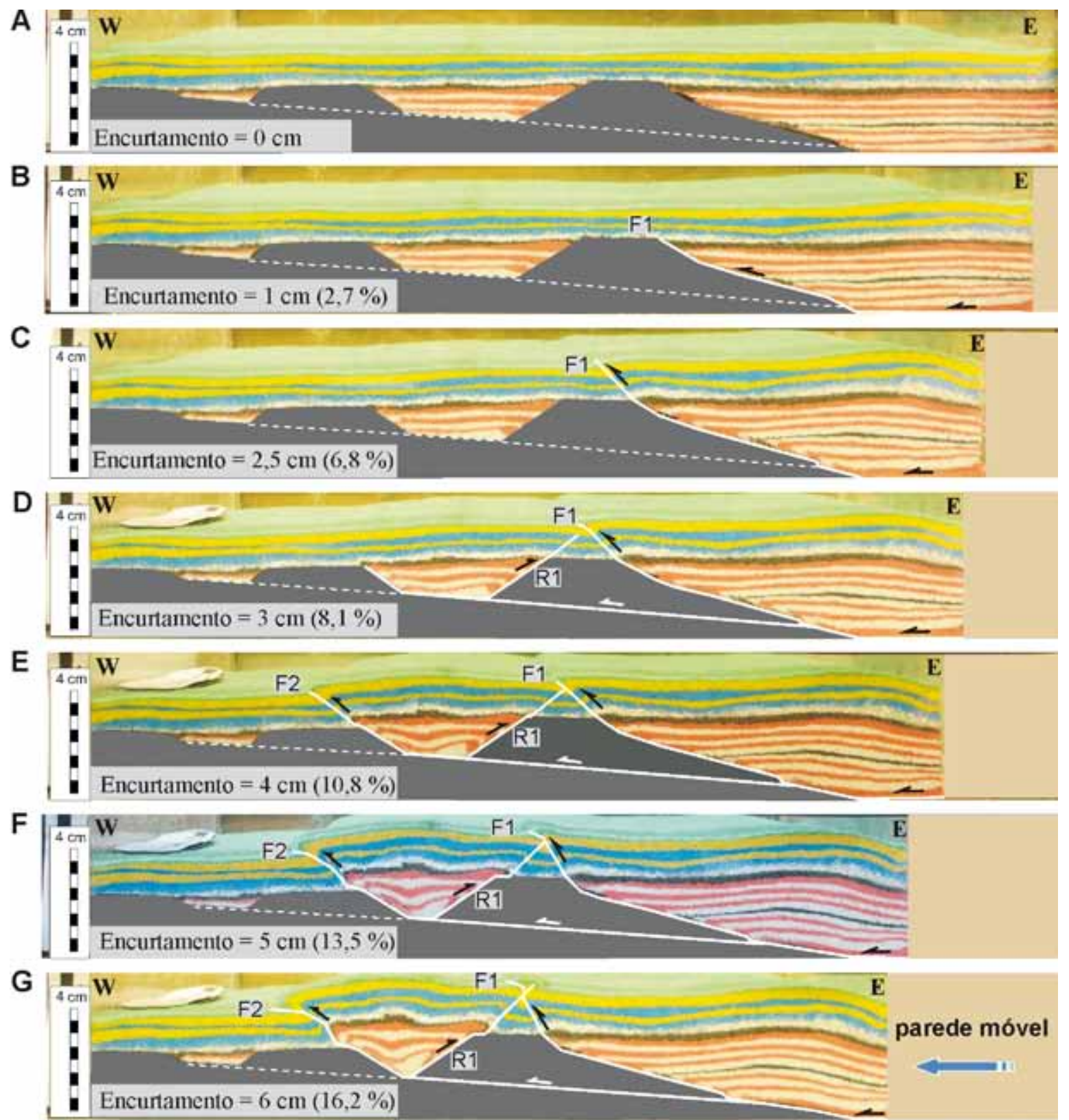

Figura 6 - A a G - Deformação progressiva do experimento III, com uma camada basal de cristais de micas na base da megassequência superior. $F 1$ e $F 2=$ falhas reversas; $R 1=$ retroempurrão. $A$ linha tracejada nas figuras $A-D$ representa a falha normal intracrustal, antes de sua reativação.

as feições que caracterizam a interferência das falhas são fortemente dependentes da reologia do material analógico que está posicionado na base da sequência pós-rifte. As figuras 7, 8 e 9 sugerem que a interferência das falhas também é controlada pela magnitude da deformação, aparentemente mais elevada próximo às paredes laterais da caixa dos experimentos (cortes de 2 e de $18 \mathrm{~cm}$ ) do que no centro.

No experimento I, constituído apenas por areia seca, formaram-se em sequência, após um total de 4 $\mathrm{cm}$ de encurtamento, o empurrão $\mathrm{F} 2$, o retroempurrão (R1) e um empurrão, secundário, F3. Esse último sobe progressivamente sobre o retroempurrão.

No domínio do Alto do Boqueirão, o Experi- mento I mostra que o progressivo crescimento do retroempurrão (R1) está associado, inicialmente, a uma pequena rotação horária da falha reversa F1 (Figs. 4D e E). Observa-se nas figuras $4 \mathrm{E}$ e $\mathrm{F}$ que, entre 4 e $5 \mathrm{~cm}$ de encurtamento, o retroempurrão se estendeu até o topo da sequência pós-rifte provocando rompimento e concomitante arrasto do segmento superior de F1, no sentido leste.

Nas fotografias das figuras $4 \mathrm{~F}$ e $3 \mathrm{G}$ e nos cortes internos (Fig. 7), nota-se que a superposição das falhas R1 e F1 forma, no domínio do Alto do Boqueirão, um relevo positivo caracterizado por uma estrutura cuja geometria se assemelha a duas dobras em caixa de fechamentos opostos (Figs. 4G e 7). O exame cuidadoso 

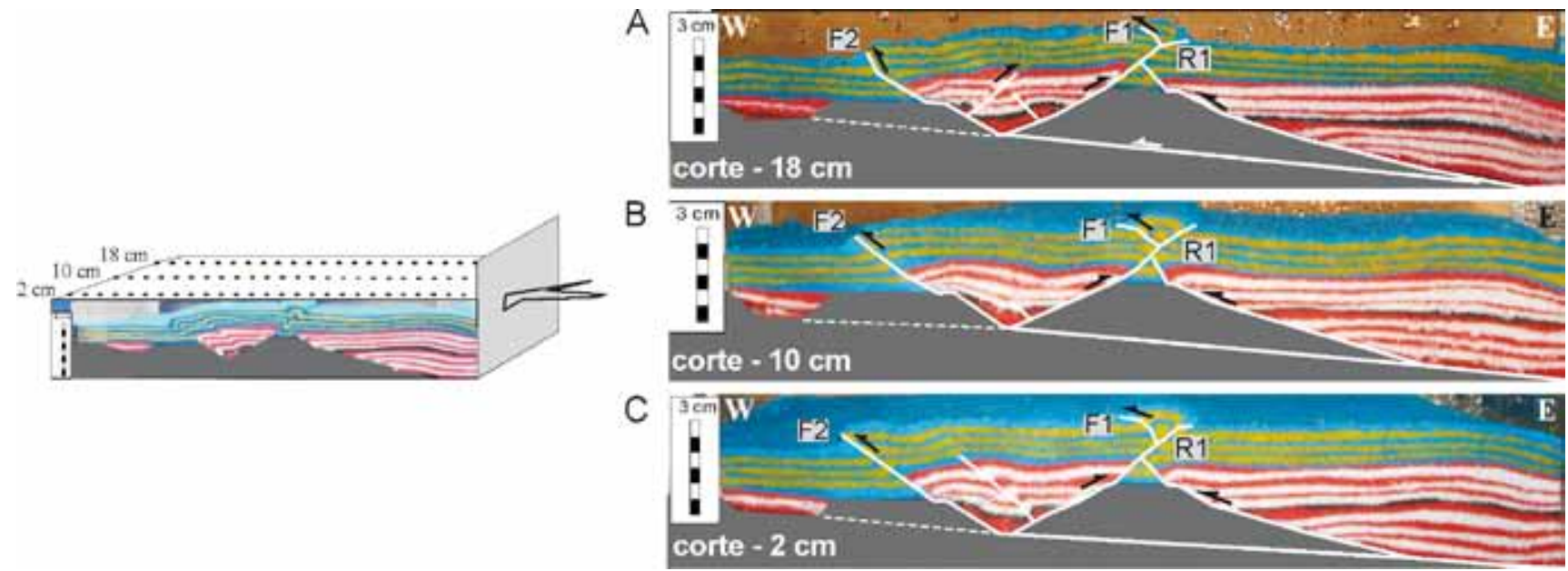

Figura 7 - A, B e C-Cortes no interior do experimento I, após o encurtamento final, paralelos ao transporte tectônico. Observar que, sem o efeito do atrito lateral da parede de vidro, a deformação é ligeiramente diferente, e heterogênea, em 3D. A esquerda, bloco diagrama com a posição dos cortes.

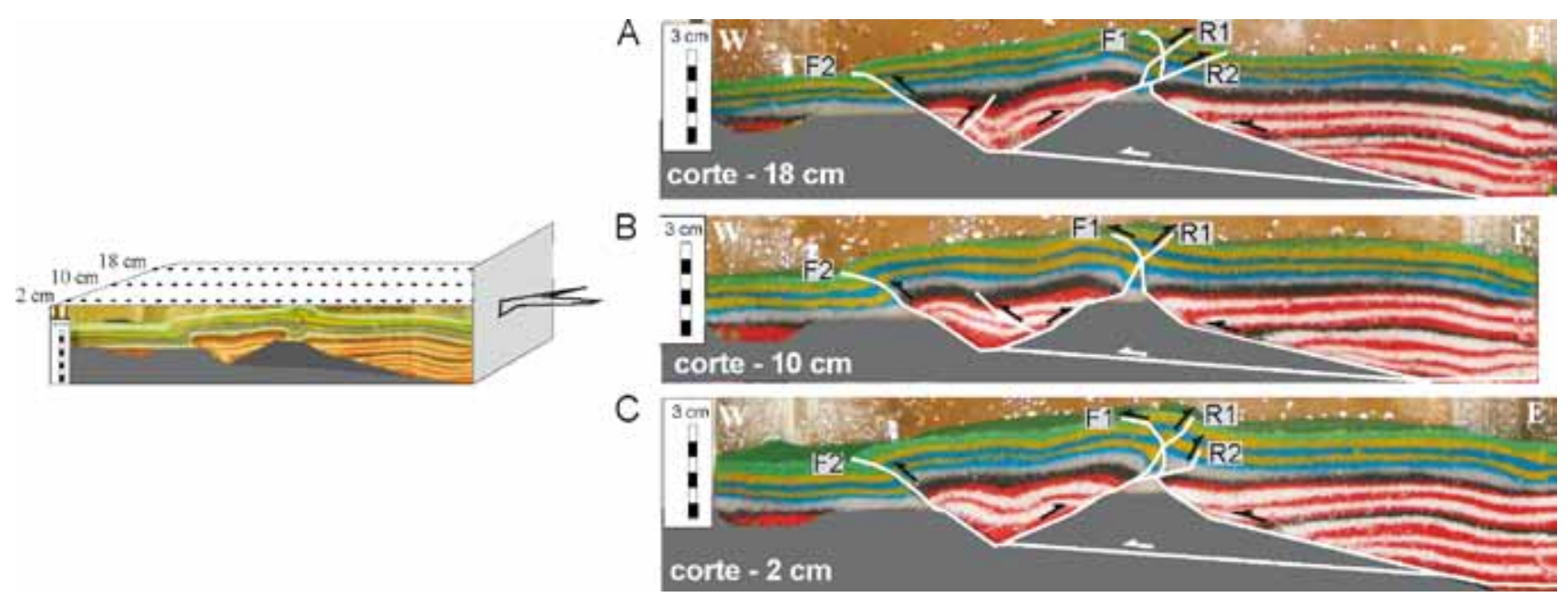

Figura 8 - A, B e C-Cortes no interior do experimento II, após o encurtamento final, paralelos ao transporte tectônico. Observar que, sem o efeito do atrito lateral da parede de vidro, a deformação é ligeiramente diferente, e heterogênea, em 3D. A esquerda, bloco diagrama com a posição dos cortes.

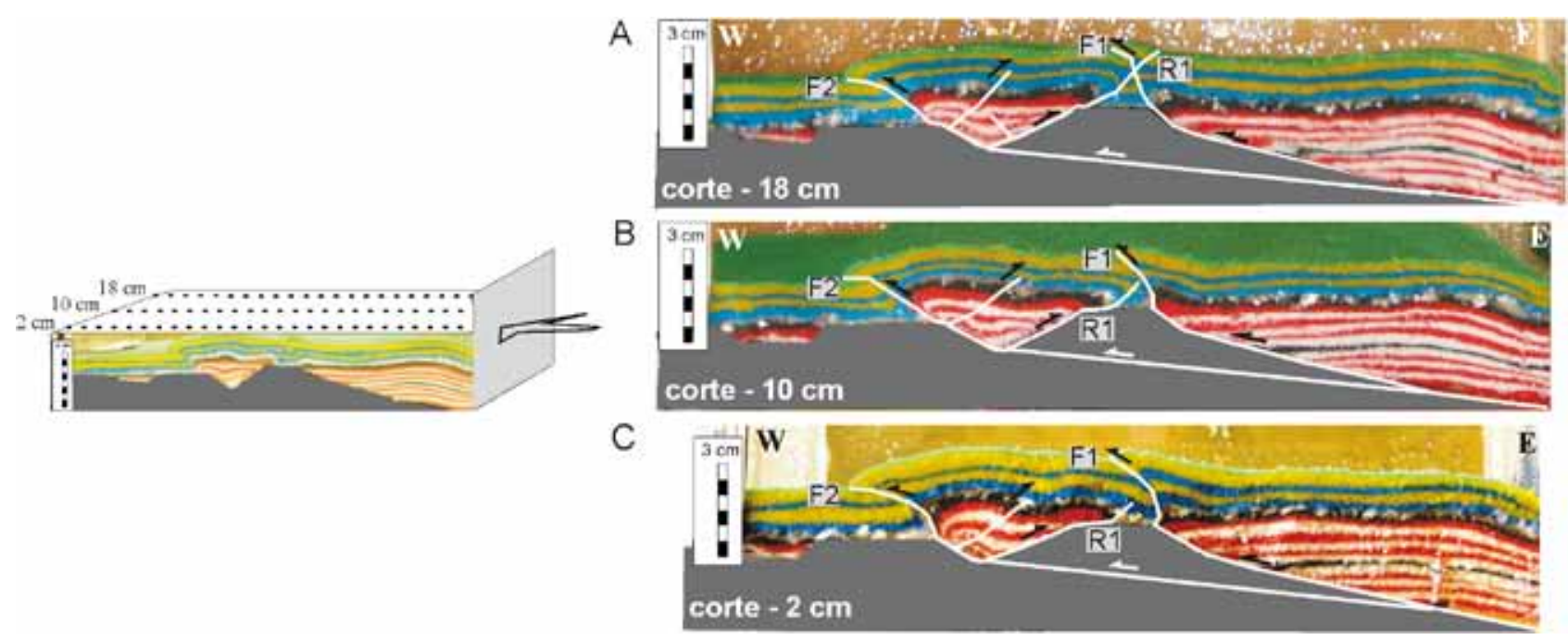

Figura 9 - A, B e C-Cortes no interior do experimento III, após o encurtamento final, paralelos ao transporte tectônico. Observar que, sem o efeito do atrito lateral da parede de vidro, a deformação é ligeiramente diferente, e heterogênea, em 3D. A esquerda, bloco diagrama com a posição dos cortes. 
desta estrutura revela que a dobra antiformal, de topo, se desenvolve como uma fault-propagation fold. Esta corta uma dobra preexistente também induzida por falha. A dobra antiformal mostra vergência no sentido contrário ao transporte tectônico e, em $3 \mathrm{D}$, uma forte assimetria especialmente nos cortes internos (de $2 \mathrm{~cm}$ e de $18 \mathrm{~cm}$ ) (Fig. 7). O último fato indica que o translado da sequência sin-rifte sobre o retroempurrão ocorreu de forma heterogênea.

O experimento II, com camada de microesferas de vidro, mostra, no domínio oeste, grande similaridade com o experimento I, com exceção do empurrão secundário $\mathrm{F} 3$ que, neste experimento, é inexpressivo. No domínio do Alto do Boqueirão, a camada basal de microesferas exerce forte influência sobre o encurtamento progressivo. As propriedades friccionais deste material, o ângulo de atrito interno e a tensão cisalhante coesiva, mais baixas do que na areia seca, justificam o comportamento levemente plástico da camada basal que se torna mais espessa sobre o Alto do Boqueirão (Figs. 5G e 8). O experimento mostra ainda que o comportamento plástico da camada basal se transmite para as camadas superiores, de areia seca, uma vez que o retroempurão (R1), ao se estender até o topo da sequência pós-rifte, rotaciona, aumentando o ângulo de mergulho e, ao mesmo tempo, causa a verticalização da falha F1 (Figs. 5E a G). Posto que o crescimento do retroempurrão R1, no interior da sequência pós-rifte, representa um comportamento rúptil e a rotação das falhas, um comportamento plástico, caracteriza-se, aqui, uma deformação rúptil-dúctil. Nas fotografias das figuras $5 \mathrm{E}$ a G observa-se que, apesar do retroempurão (R1) seccionar a falha $F 1$, esta não chega a deslocar o seu segmento superior, como acontece no experimento I. Ao invés disto, as duas falhas se juntam, na sua porção mediana, e se aproximam progressivamente na porção inferior, sobre o Alto do Boqueirão. É interessante notar, no entanto, que no corte de $18 \mathrm{~cm}$ (Fig. 8A), a falha F1 é atravessada e deslocada por um segundo retroempurrão (R2). Esta falha é também registrada no corte de $2 \mathrm{~cm}$ (Fig. 8C), mas sem causar translação. Já, a seção central, de $10 \mathrm{~cm}$ (Fig. 8B), apenas revela um forte encurvamento do traço da falha $\mathrm{F} 1$, no caso uma feição bastante expressiva em todos os cortes.

À semelhança do experimento I, no experimento II a superposição das falhas evidencia uma estrutura do tipo dobra em caixa com fechamento antiformal, próximo ao topo da sequência pós-rifte, e fechamento sinformal sob as duas falhas. Neste experimento, o sinforme apresenta um achatamento expressivo que, mais uma vez, mostra a influência da camada basal de microesferas de vidro na reologia da sequência pós-rifte.

A deformação progressiva do experimento III, com uma camada de cristais de micas, possui características comparáveis àquelas do experimento II. No entanto, as feições plásticas são menos expressivas. Assim, por exemplo, ocorre uma rotação menor das falhas $\mathrm{F} 1$ e R1 no domínio do Alto do Boqueirão (comparar as figuras $5 \mathrm{G}$ e $6 \mathrm{G}$ ). A comparação dos gráficos "Ângulo de mergulho da falha F1 x Encurtamento", da figura 10,
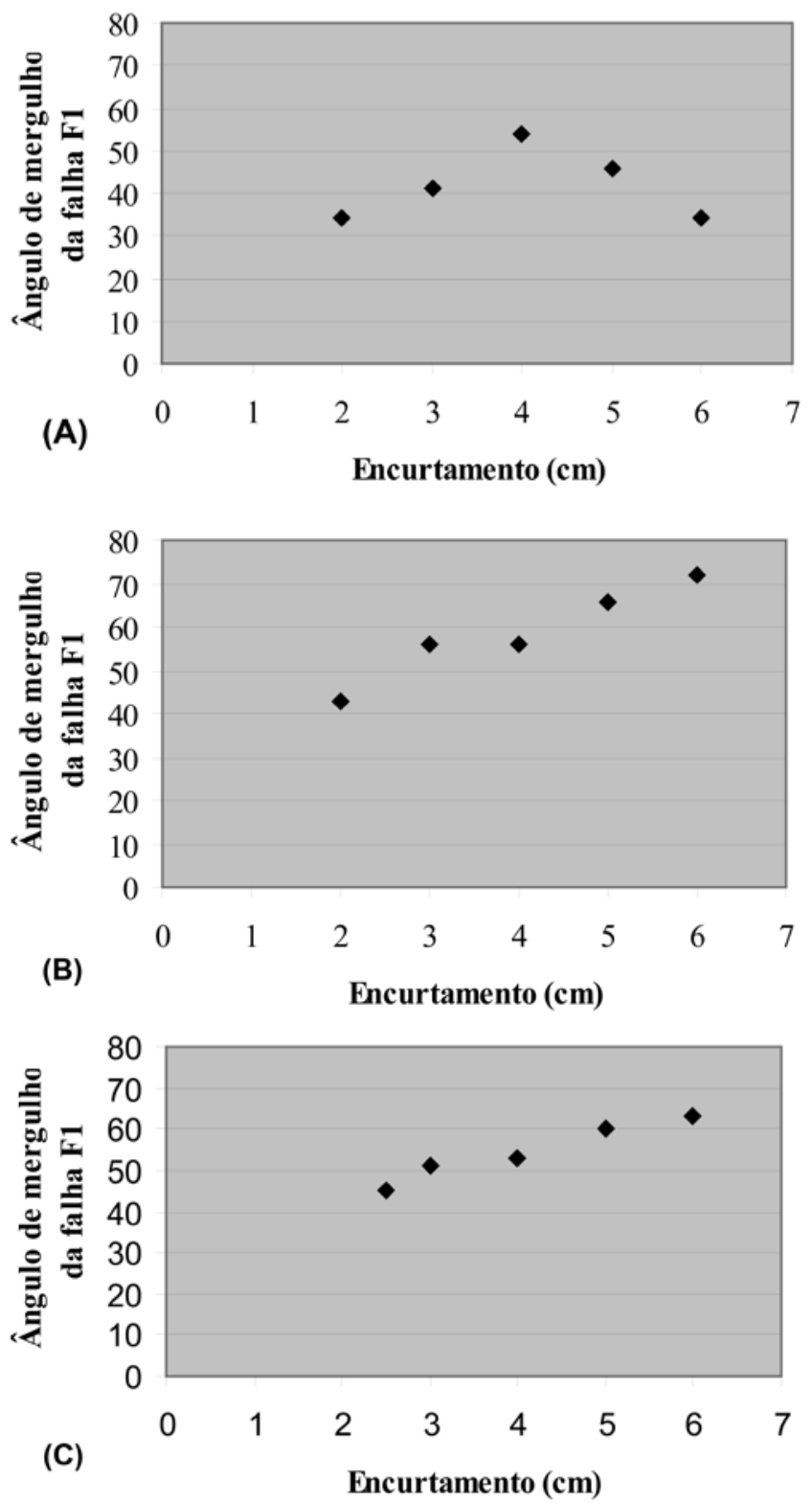

Figura 10 - Gráficos "Ângulo de mergulho da faIha F1 x Encurtamento", que mostram a rotação da falha F1 decorrente do translado da sequencia pré-rifte sobre a face ocidental do Alto do Boqueirão. A-Experimento I (de areia); $B$ - Experimento II (de areia com uma fina camada de microesferas de vidro); C-Experimento III (de areia com uma fina camada de cristais de mica).

revela que no experimento II a rotação da falha F1 é aproximadamente $10^{\circ}$ maior do que no experimento III.

Quando a falha reversa F1 se estende sobre o Alto do Boqueirão (após encurtamento de $2 \mathrm{~cm}$ ), o seu ângulo de mergulho varia de $33^{\circ}, 43^{\circ}$ a $45^{\circ}$ nos experimentos I, II e III, respectivamente. A rotação maior da falha F1 nos experimentos II e III é relacionada ao espessamento dúctil da camada incompetente na base da sequência pós-rifte.

O gráfico da figura $10 \mathrm{~A}$ mostra que, no experi- 
mento I, o ângulo de mergulho da falha F1 diminui após $4 \mathrm{~cm}$ de compressão. $O$ decréscimo no valor desse ângulo coincide com o rompimento da falha $\mathrm{F} 1 \mathrm{em}$ dois segmentos, quando este é atravessado pelo retroempurrão R1. O fato sugere um relaxamento, possivelmente relacionado à resposta elástica da camada de areia à deformação.

\section{DISCUSSÃO}

Os resultados dos modelos experimentais Os modelos desenvolvidos simularam com sucesso a progressiva interferência de falhas reversas, de vergências opostas, sobre um bloco rígido, não-aflorante, em um processo de inversão tectônica. A estruturação tectônica foi produzida pelo comportamento peculiar de um bloco rígido, posicionado sobre uma falha intracrustal de baixo ângulo, que inicialmente manteve-se fixo e, posteriormente com o aumento da deformação, foi transladado para oeste movimentando-se sobre a referida falha. No estado fixo, o bloco agiu como um obstáculo e, quando móvel, como um indenter. Como resultado desse processo, houve o desenvolvimento de uma falha de empurrão na sua face oriental e uma de retroempurrão do lado oposto. Essas duas estruturas se interceptam na sequência pós-rifte, sobre o bloco, caracterizando essa região como de dupla vergência.

Inúmeros são os trabalhos de modelagem física analógica que analisam a atuação de indenters em uma tectônica compressiva (por exemplo, Macedo \& Marshak 1999, Bonini et al. 1999). Bonini et al. (1999) descrevem em caixas de areia a atuação de indenters rígidos, em cunha, caracterizados por diferentes ângulos de mergulho. Os autores, que só empregaram areia como material analógico mostraram a formação progressiva de falhas de empurrão no antepaís e a ascensão destas sobre o indenter, no sentido contrário à polaridade tectônica, quando o ângulo de mergulho da cunha é $\leq 45^{\circ}$. No presente trabalho, o bloco rígido possui geometria em cunha, com face frontal de baixo ângulo, mas, diferente do estudo desenvolvido por Bonini et al. (1999), o bloco é coberto por uma sequência pós-rifte.

Nos experimentos desenvolvidos, a deformação, no domínio do Alto do Boqueirão, variou de rúptil (experimento I) a rúptil-dúctil (experimentos II e III). Nos três casos, a ascensão da sequência sin-rifte sobre a face ocidental do Alto do Boqueirão causa uma compressão local sobre o bloco rígido. No experimento I, esta deformação é acomodada por uma falha reversa (R1) que secciona a falha mais antiga (F1) e cujo segmento superior é deslocado para leste. Nos dois outros experimentos, predomina a deformação plástica, pela rotação horária da falha mais antiga e/ou pelo seu encurvamento (Figs. 8 e 9).

Segundo Panien et al. (2006), um horizonte de $1 \mathrm{~mm}$ de espessura de microesferas de vidro em contato com uma superfície basal de PVC causa, na camada sobreposta de areia, uma redução no ângulo de atrito basal de $37 \%$. Esta redução facilita a transmissão dos esforços durante o encurtamento crustal. Os resultados do presente trabalho permitem sugerir que a camada basal, incompetente, da sequência pós-rifte, além de exercer influ- ência sobre a cobertura, também interfere no comportamento da sequência subjacente. Este fato é balizado pela ascensão diferenciada da estrutura $p o p-u p$ no domínio a oeste do Alto do Boqueirão, que se apresenta simétrica nos experimentos II e III e assimétrica no experimento I, este último sem a anisotropia basal da sequência pósrifte. Além disto, apenas o experimento I desenvolve, de forma homogênea, um terceiro empurrão, a falha F3.

Percebe-se, nos experimentos II e III, que as microesferas de vidro e os cristais laminados de micas, apesar de constituírem materiais de características (composição e forma) muito diferentes, transmitem os esforços de maneira similar. A deformação no interior da camada de microesferas de vidro ocorre por rotação entre grãos e, naquela dos cristais laminados de micas, pelo deslizamento cristal sobre cristal, com rotação secundária. Conforme a tabela 1, as microesferas de vidro possuem coesão mais elevada do que os cristais de mica, mas ângulo de atrito interno mais baixo, que é responsável pelo comportamento mais plástico. Esse fato justifica a maior rotação das falhas $\mathrm{F} 1$ e R geradas no experimento II em relação ao experimento III, no domínio do Alto do Boqueirão (Fig. 10).

O exemplo natural da serra da Água Fria A modelagem analógica foi desenvolvida com o intuito de se compreender melhor a mecânica e a cinemática da inversão tectônica positiva com embasamento envolvido da região da serra da Água Fria, conforme tese de Hercos et al. (2008). Apesar das simplificações inerentes a experimentos de modelagem física analógica, o trabalho experimental conseguiu simular feições importantes: a vergência das estruturas, contrária à direção do transporte tectônico regional, e a deformação rúptil-dúctil que induziu a formação de dobras do tipo fault-propagation folds. Nos experimentos, esta deformação resultou da introdução de uma camada incompetente na base da sequência pósrifte, e, na interpretação dos autores acima, das seções sísmicas, da presença de rochas do tipo pelitos e calcários no Grupo Macaúbas. Desta forma, apontase os experimentos II e III como os mais representativos da deformação ocorrida na região da serra da Água Fria, e entre estes, o experimento II, que contem uma camada de microesferas de vidro, possui o comportamento rúptil-dúctil mais expressivo.

No domínio oeste do Alto do Boqueirão foram interpretadas, na seção sísmica, quatro falhas reversas com polaridade voltada para o pós-país. A causa do número de falhas ser maior na natureza do que nos experimentos exige um estudo experimental mais aprofundado. Conforme os trabalhos desenvolvidos por Bonini et al. (1999), este fato possivelmente está relacionado com o ângulo e mergulho da face ocidental da cunha que representa o Alto do Boqueirão nos experimentos.

CONCLUSÕES Os modelos experimentais, apesar de representarem uma simplificação da deformação que ocorre na natureza, produziram feições que mostram uma boa correlação com as estruturas interpretadas na seção 
sísmica posicionada a oeste da serra da Água Fria.

Os experimentos demonstraram que:

- em modelos de areia, um bloco rígido posicionado em subsuperfície, gera falhas com dupla vergência na cobertura pós-rifte, se durante a deformação progressiva este mudar o seu papel de obstáculo para indenter;

- a intercalação de uma camada de baixo coeficiente de atrito interno em um pacote de areia, de caráter rúptil, influencia a reologia de toda a sequência. Em regime de compressão esta causa um comportamento rúptil-dúctil;

- nas mesmas condições de deformação, uma camada de microesferas de vidro confere à areia seca, um comportamento mais plástico do que uma camada de cristais de mica;
- a hipótese de que, no domínio do Alto do Boqueirão a vergência contrária ao sentido da polaridade tectônica regional tenha sido causada pela indentação do bloco do embasamento, em profundidade, é geométrica e cinematicamente possível.

Além disso, os experimentos sugerem que a possível presença de uma camada basal incompetente na sequência pós-rifte tenha causado um comportamento rúptil-dúctil das rochas do protótipo e, em consequência, a formação de fault-propagation folds.

Agradecimentos Os autores agradecem à Fapemig pelo auxílio financeiro (processo CRA 871/06) e à Petrobras e à ANP pela cessão dos dados sísmicos. Com criteriosas sugestões três revisores anônimos em muito contribuíram para o aprimoramento do presente artigo.

\section{Referências}

Alkmim F.F., Brito Neves B.B., Alves J.A.C. 1993. Arcabouço tectônico do Cráton do São Francisco - uma revisão. In: Dominguez J.M. \& MISI A. (eds). O Cráton do SãoFrancisco. Reunião preparatória do II Simpósio sobre o Cráton do São Francisco, Salvador, SBG/Núcleo BASE/ SGM/CNPq. p. 45-62.

Bonini M., Sokoutis D., Talbot C.J., Boccaletti M. 1999. Indenter growth in analogue models of Alpine-type deformation. Tectonics, 18:119-128.

Chapple W.M. 1978. Mechanics of thin-skinned fold-andthrust belts. Geological Society of America Bulletin, 89:1189-1198.

Davis D.M. \& Engelder T. 1985. The role of salt in fold-andthrust belt. Tectonophysics, 119:67-88.

Davy P. \& Cobbold P.R. 1988. Indentation tectonics in nature and experiment 1. Experiments scaled for gravity. Bulletin of the Geological Institution of the University of Uppsala, 14:129-141.

Davy P. \& Cobbold P.R. 1991. Experiments on shortening of a 4-layer model of the continental lithosphere. Tectonophysics, 188:1-25.

Ellis P.G. 1988. Analogue model studies of the kinematics of extensional faulting. $\mathrm{PhD}$ thesis, University of London.

Gomes C.J.S., Ferreira J.E., Pereira Filho M. 1999. Modelos físicos de falhas de empurrão com trajetória em degrau. Revista Brasileira de Geociências, 29:539-548.

Gomes C.J.S., Silva F.C.A., Rosenau M., Klinkmüller M. 2009. As propriedades mecânicas da areia de quartzo medidas em um Ring-Shear Tester. In: SBG, Simp. Nac. Estudos Tectônicos 12, Intern. Symp. Tectonics, 6, Programa e Resumos, p. 47.

Handin J. 1966. Strength and ductility. In: Clark, S.P. Jr. (ed.) Handbook of Physical Constants. Geological Society of America, Memoir, 97:223-289.

Hercos C.M., Martins-Neto M.A., Danderfer Filho A. 2008. Arcabouço estrutural da Bacia do São Francisco nos arredores da Serra da Água Fria (MG), a partir da integração de dados de superfície e subsuperfície. Revista Brasileira de Geociências, 38:197-212.
Hercos C.M. 2008. Arcabouço tectono-estratigráfico da Bacia do São Francisco nos arredores das serras da Água Fria e da Onça, porção centro-norte do estado de Minas Gerais. Ouro Preto, Dissertação de Mestrado, Departamento de Geologia, Univ. Federal de Ouro Preto, 207 p.

Hubbert M.K. 1937. Theory of scale models as applied to the study of geologic structures. Geological Society of America Bulletin, 48:1459-1520.

Hubbert M.K. 1951. Mechanical basis for certain familiar geologic structures. Geological Society of America Bulletin, 62:355-372.

McClay K.R. 1990. Extensional fault systems in sedimentary basins: a review of analogue model studies. Marine and Petroleum Geology, 7:206-233.

Macedo J.M. \& Marshak S. 1999. Controls on the geometry of fold-thrust belt salients. Geological Society of America Bulletin, 111:1808-1822.

Panien M., Schreurs G., Pfiffner A. 2005. Sandbox experiments on basin inversion: testing the influence of basin orientation and basin fill. Journal of Structural Geology, 27:433-445.

Panien M., Schreurs G., Pfiffner A. 2006. Mechanical behaviour of granular materials used in analogue modeling: insights from grain characterization, ring-shear tests and analogue experiments. Journal of Structural Geology, 28:1710-1724.

Ramberg H. 1981. Gravity, Deformation, and the Earth's Crust. New York, Academic Press, 387 p.

Schellart W.P. 2000. Shear test results for cohesion and friction coefficients for different granular materials: scaling implications for their usage in analogue modeling. Tectonophysics, 324:1-16.

Storti F. \& McClay K. 1995. Influence of syntectonic sedimentation on thrust wedges in analogue models. Geo logy, 23:999-1002.

Manuscrito ID 17006

Submetido em 11 de março de 2010 Aceito em 22 de novembro de 2010 